\title{
Complexity of Interaction in a Second Language Conversation Group: An Exploratory Study
}

\author{
Melanie Lynn D’Amico \\ Department of Languages, Literatures \& Linguistics, Indiana State University, Terre Haute, IN, USA \\ Email: mdamico@indstate.edu
}

Received 9 July 2015; accepted 11 August 2015; published 14 August 2015

Copyright (C) 2015 by author and Scientific Research Publishing Inc.

This work is licensed under the Creative Commons Attribution International License (CC BY).

http://creativecommons.org/licenses/by/4.0/

(c) (i) Open Access

\begin{abstract}
The aim of this research was to explore the nature of conversation in a weekly second language Italian conversation group. Analysis of conversations focused on the range of topics and verbal structures used by learners. Additional analysis was completed to determine if learners engaged in negotiation of meaning or form during conversations. Results revealed that learners used a range of topics and verbal structures from Beginner level to Advanced level indicating that learners challenged themselves to produce high quality, natural conversation. Learners also showed some use of negotiation during conversations to repair communication breakdowns, principally to address meaning; however, the amount of negotiation was low when compared to task-based interaction designed to elicit negotiation.
\end{abstract}

\section{Keywords}

Conversation Group, Learner Interaction, Natural Conversation, Second Language, Range of Topics, Verbal Structures, Negotiation of Meaning

\section{Introduction}

Second language conversation groups, also referred to as language tables or language coffee hours, are common on campus at US universities and are designed to allow students studying a foreign or second language (L2) to have meaningful interaction in a real-world setting. These groups are often promoted and valued by language instructors as a means for additional practice and language learning outside of the classroom. In many cases the structure of the conversation group is informal; groups are often student-run or have only minimal instructor guidance. The relaxed atmosphere provided by such groups encourages natural, spontaneous conversation that 
can be difficult to have in the classroom. However, with this type of amorphous plan one might wonder what exactly happens in one of these groups on a regular basis. Do students choose easy topics with simple vocabulary and grammatical structures? Or do they challenge themselves with more complex interaction? If students are using only basic language skills, can we really expect them to make improvements in their oral communication as a result of their participation in these groups? As language instructors and researchers, we may see conversation groups as beneficial, yet we need to have information about how such groups function and about the nature of the interaction that students receive. Although much research has been completed on conversations in the classroom or laboratory ${ }^{1}$, research on informal conversation groups is limited. With this in mind, the current study aimed to discover more about an L2 conversation group through exploring the interaction at weekly meetings of an Italian language table at a US university.

\section{Literature Review}

\subsection{Input and Interaction}

Second language acquisition (SLA) researchers have long valued oral communication as part of the L2 learning process. Three key hypotheses that address this importance are Long's Input and Interaction Hypothesis (1983), Swain's Output Hypothesis (1993, 2000), and Gass' Input and Interaction Hypothesis (1997). These hypotheses discuss the necessity for learners to receive and process comprehensible input and then produce comprehensible output that will allow for feedback from an interlocutor. The cycle of input to output to feedback (new input) provides the learner with an opportunity for checking and testing known information about the L2 as well as offering new information that can be highly-focused on the needs of the learner. As a learner interacts with another speaker, there is the potential for a breakdown in communication caused by a misunderstanding. According to Long, these breakdowns can lead to negotiation wherein the interlocutors attempt to repair the breakdown by asking questions, providing new information, and/or rephrasing an utterance. The act of negotiation offers the learner specific information that he/she needs in that moment assisting the flow of conversation and affording the learner L2 knowledge that may be lacking from his/her system. Furthermore, as the learner produces output, he/she has the opportunity for hypothesis testing about the language (Swain, 2000) that is confirmed or refuted by the feedback received from the interlocutor. According to Swain, output encourages learners to analyze language on a deeper level and can offer more linguistic development than input, due to the extra mental effort required to produce a statement in the L2. Such output is also called "pushed output" by Swain because the feedback is "pushing" the learner to respond.

Following these hypotheses, ideally learners should interact with a native speaker (NS) or a highly-advanced non-native speaker (NNS), as it is believed that learners will be able to gain the necessary information to correct conversational breakdowns when communicating with a more knowledgeable speaker. However, research into learner-learner interaction (Bruton \& Samuda, 1980; Long \& Porter, 1985; Ohta, 1995; Pica, Lincoln-Porter, Paninos, \& Linnell, 1996; Mackey, 1999; Del Pilar García Mayo \& Pica, 2000; Mackey, Oliver, \& Leeman, 2003; Adams, 2007; Sato \& Lyster, 2007; Sato, 2007; Fernández Dobao, 2012) has found that even at the same learner level, negotiation and breakdown repair are still possible if one interlocutor has the necessary information. Nevertheless, if neither learner knows how to repair the breakdown, it is likely that the interlocutors will abandon the topic or end the conversation. In a conversation group that is comprised of learners from various levels it is logical to expect that negotiation and breakdown repair will be possible especially since there are many different sources of L2 information. This type of assistance from others may not be possible in a typical one-on-one conversation. Moreover, in the relaxed atmosphere of a conversation group, learners may feel more comfortable requesting assistance from others.

Looking more in-depth, certain advantages can be seen for incorporating learner to learner interaction in the acquisition process. In their research on interaction and the nature of feedback, Mackey, Oliver and Leeman (2003) investigated low-intermediate English L2 speakers interacting with other learners and with NSs. They discovered that for the adult dyads, when learners provided feedback to other learners, they offered significantly more opportunities for modified output than NSs. Whether this was due to lack of knowledge or unwillingness to correct another learner, this finding suggests that when interacting with another NNS, a learner may have more opportunity for pushed output to solve communication problems than when interacting with a NS who

\footnotetext{
${ }^{1}$ Mackey (2007), pp. 4-9 provides tables of citations of classroom and laboratory interaction research and is an excellent starting point for investigating prior research.
} 
may simply provide the necessary information for the learner.

Similar to the results from Mackey et al., Sato and Lyster's (2007) research of EFL learners in Japan, found that in learner-learner dyads, learners provided significantly more elicitation feedback which could lead to pushed output than NSs, who provided significantly more reformulation feedback, i.e. providing the correct form. Results also showed that learners produced significantly more modified output in the learner-learner dyads than in the learner-NS dyads; nonetheless, this modified output was equally likely to occur after elicitation or reformulation feedback. Perhaps more importantly, in their qualitative analysis of learner perceptions, Sato and Lyster discovered that learners felt more comfortable asking questions about incorrect utterances with other learners and were more actively engaged in the interaction during the learner-learner dyads. When participating in conversations with NSs, the learners relied on the "expert" or "perfect speaker" to guide the conversation and they took on a more passive role allowing NSs to dominate the conversation.

Sato (2007) also investigated EFL learners in Japan participating in learner-NS dyads and learner-learner dyads. His results complement Sato and Lyster's in that the learners reported feeling at ease and under less pressure conversing with other learners than with NSs. Learners also indicated that they had more time to formulate responses and that they noticed grammatical forms more during learner-learner conversation. Sato also focused on grammatical form errors during these conversations and found that in both contexts it was unlikely to have negotiation of form. However, when grammatical errors occurred, learners were more likely to modify output when speaking to other learners.

Taking learner-learner interaction researcher further, Adams (2007) explored whether or not learners could show evidence of learning after participating in interaction with other learners. Her study of ESL learners from a variety of L1 backgrounds revealed that the interaction and special attention to form provided during the interaction assisted L2 learning. Her results suggested that interaction can help forms to become more salient thus leading to greater learner awareness of the form. In addition, her findings showed that learners often used self-correction after hearing other learners repeat their error.

Considering these studies together, we can see that interaction in the learner-learner context is likely to have more feedback that initiates learners to produce modified output. While it is less likely that learners will directly provide L2 knowledge, there is a sense that learner-learner interaction may require more mental effort on the part of the learner which may help the learner to know more precisely about what he/she is able to accomplish in the L2 (following Swain, 2000). Furthermore, the learner-learner context is seen as comfortable and favorable to active participation in conversations. Subsequently, it is logical to conclude that conversations groups that are comprised primarily of learners would offer the same type of interaction in a pleasant setting thus showing similar benefits to language learners. However, we should keep in mind that this prior research used controlled language tasks designed to initiate negotiation; in an open-ended conversation group, it is possible that such conditions may not be found.

\subsection{Conversation Groups}

Despite the wealth of studies completed in classrooms and laboratories, there are few that look at natural learner conversation in conversation groups. Three recent studies, Ziegler, Seals, Ammons, Lake, Hamrick and Rebuschat (2013), McDonough and Hernández González (2013), and Tudini (2013), do explore the nature of interaction in less-structured conversation groups or pairs and are discussed below.

The German conversation groups from Ziegler et al. (2013) are the most closely related to the group investigated in the current study in that they were comprised primarily of students of various proficiency levels and were designed to offer naturalistic conversation practice in a face-to-face setting. Different from the current study, Ziegler et al.'s groups were created for the purposes of the research and were overseen by a NS moderator. The moderator's role was to encourage learner participation and to provide topics that would motivate continued discussion. This exploratory study was designed to research L2 conversational style and the changes that occurred to that style over time. Results found that over the six week period, learners changed their participation in the conversations by becoming more active or more passive interactors. Learners who better adapted to the German discourse structure employed by the NS moderator became more active overall, while those that appeared less inclined to adapt their conversation style became more passive during conversations.

Findings from Ziegler et al. also revealed that all learners participated in collaborative conversation that had instances of negotiation and feedback on incorrect utterances that led to modified output. Despite the presence of the NS, learners provided information about form and meaning on their own to assist each other thus showing 
that they did not rely on the moderator solely as the source of L2 information. Learners found the conversation group to be a supportive and comfortable atmosphere that was ideal for language practice and increased speaking confidence. Even more passive learners found this to be true and reported that they found the conversation group to be beneficial to their L2 understanding in that they were able to attend to the input provided by others during the conversation.

With a comparable design to Zeigler et al., McDonough and Hernández González (2013) investigated conversation groups formed by ESL preservice teachers (English NSs or advanced NNSs) and ESL learners. The goal of the research was to explore language production opportunities offered during these conversation group sessions. Unlike Zeigler et al., the conversation groups from McDonough and Hernández González did not appear to offer learners as much naturalistic practice since results revealed that the preservice teachers dominated the conversations. Analysis indicated that the preservice teachers had a tendency to treat the conversations as teaching sessions rather than more naturalistic conversations as much time was spent on instructions or management of the conversation. Additionally, McDonough and Hernández González stated that "...preservice teachers may have regarded themselves as the primary source of content knowledge." (p. 309) thus leading them to interact more in the conversation as a means of providing that knowledge to the learners. With regard to the learners, it was found that they produced the greatest amount of talk in the content sections of the discussion and this talk frequently consisted of referential and clarification questions. The results also revealed that learners did not typically speak about their own lives and experiences during these discussions. Given the style of moderation utilized by the preservice teachers, it is unlikely that these conversation groups provided the comfortable, less-pressure atmosphere that is encouraged in most language tables. Motivated by their findings, McDonough and Hernández González suggest that conversation group moderators receive sufficient training to assist them in providing greater opportunities for learner participation and to acknowledge the difference between formal lessons and informal conversation groups.

Exploring another option for natural conversation, Tudini (2013) investigated the interaction between learners and NSs in an online chatting conversation on Shared Talk. Similar to idea of conversation groups, the website www.sharedtalk.com is a language exchange community that allows learners to connect with NSs and other learners across the globe in paired or group discussions in voice or text chatting formats. In her study, Tudini analyzed the form-focused feedback provided by an Italian NS to an L2 Italian learner during their paired chat sessions. While different from a face-to-face conversation group, the paired chat sessions do share common features with language tables in that conversation topics are open, the atmosphere is relaxed and comfortable, and the goal is for conversational language practice rather than a specific language learning plan. With regards to feedback on form, Tudini found that the NS participant tended to offer corrections in the form of recasts while maintaining the topic of discussion with the learner. This type of feedback appeared to be both informative and nonintrusive for the learner. The learner reacted to the feedback positively through acknowledgement of the correction and frequently thanking the NS. Results also found that the learner would often repeat the correction in subsequent lines of chat seemingly as a method of reinforcing the correction. This type of correction did not appear to discourage the learner's conversation practice. Finding this type of balance between natural conversation and corrective feedback is often a goal of conversation groups. Following Tudini's results it appears that this can be achieved in text conversations, and we would hope it could also be done face-to-face.

From these three studies, it can be seen that natural conversation in groups or pairs can be beneficial to learners but finding the right balance of structure and freedom within the conversation appears to be essential. When given sufficient opportunity, learners appear willing and eager to practice conversation in such groups. Even if they are not as active participants, learners still seem to find value in attending conversation group sessions. We can also see that learners can be open to corrective feedback during these conversations but again achieving the right balance of instructional information to conversation time is crucial to successful interaction. Nevertheless, much is still unknown about the nature of conversation in these types of groups and it behooves us as researchers and language instructors to explore the language practice opportunities that are provided in these groups.

\section{Methodology}

The current study investigated Italian L2 learners' conversations by analyzing the spontaneous speech of learners who regularly participated at a weekly Italian conversation table. The research questions that guided the present study are as follows:

1) Do learners show a range of topic and vocabulary complexity during conversations? 
2) Do learners show a range of verbal structure complexity during conversations?

3) Do learners have instances of negotiation during conversations? If so, what is the nature of that negotiation?

\subsection{Participants}

The participants in this study were ten learners of Italian as a L2, from ages 18 to 31 . Nine of the learners were students at a US university taking classes in Italian; one of the learners was a lecturer of beginning-level Italian at the university. The learners were taking courses at a variety of levels of Italian, from beginner to advanced. Seven of the learners had a L1 of English, but there were also two learners with a L1 of Spanish and one learner with a L1 of German. As all learners spoke English, this means that these learners had two second languages. Several of the learners also had knowledge of other languages such as Spanish, French, and German. A summary of the participants can be found in Table $1^{2}$. In addition to the learners, there were two native speakers of Italian who attended the conversation table meetings who were international students at the university (both were students outside of the language department). These two native speakers and the researcher participated in the conversations but their data were not analyzed for this study.

\subsection{Data Collection}

Data were collected by voice recordings of spontaneous speech during three meetings of a weekly Italian conversation table. The Italian conversation table was started by a NS Italian instructor. His desire was to create a space for learners, instructors (NSs and NNSs), and NS Italians (non-instructors) to interact and converse in Italian. The table was a weekly event that took place at an outdoor café. Any and all Italian speakers were invited to attend. The table was publicized through classroom announcements, flyers, social networking sites (e.g. Facebook.com), and through word of mouth. The only rule that was imposed on the group was that participants try to speak only in Italian; other than that, conversation proceeded as normal: topics were chosen freely and participants were free to join into any conversation. There were no moderators or suggested topics that were used to guide conversations. Unlike groups from prior research, this group was well-established before this investigation and had not been the focus of research at any earlier time.

Recordings were made using a digital voice recorder placed at various positions on the table from week to week in order to capture a variety of conversations. In total, 5.5 hours of data were recorded over the time period of three weeks. Additionally, biographical information was collected through questionnaires to determine participant age, the current level of course being taken, L1 and other languages known.

Table 1. Participant information.

\begin{tabular}{ccccc}
\hline Student & Age & Enrolled course level & L1 & Other language known \\
Stefania & 18 & Beginning & Spanish & English \\
Sergio & 19 & Beginning & English & English \\
Violeta & 24 & Intermediate & German & French \\
Nicola & 19 & Intermediate & English & Spanish \\
Amelia & 20 & Intermediate & English & French \\
Davide & 23 & Advanced & English & English \\
Giovanni & 22 & Advanced & Spanish & none \\
Lorenzo & 22 & Advanced & English & Spanish \\
Maria & 21 & Advanced & English & German \\
Teresa & 31 & Lecturer & English &
\end{tabular}

${ }^{2}$ All names shown in the table are pseudonyms.

${ }^{3}$ Teresa was not currently enrolled in an Italian class and she rated herself at advanced-level proficiency. 


\subsection{Data Analysis}

The recording data were transcribed prior to analysis in order to better organize the different conversations, since there were often multiple conversations captured in the same recording session. In some instances, this was due to the arrival or departure of a participant, and in other cases, it was due to movement of the recorder. Most conversations were found to be between two or three participants at a time; there were no instances of a full group conversation.

This study used a grounded theory approach (Glaser \& Strauss, 1967) using coding to analyze and categorize findings. The transcriptions were analyzed though categorizing topic and vocabulary, and verbal structures used. Topics and verbal structures were not predetermined prior to transcript analysis, but rather were compiled through the reading and analysis of the conversations. The researcher divided the findings into four proficiency levels based on the topics and structures used in the textbook and syllabus of four language-based courses: Beginner, Advanced Beginner, Intermediate, and Advanced. Once all topics and structures were assigned to a proficiency level, the researcher confirmed this organization with two Italian professors to ensure proper assignation. These two Italian professors teach at all four levels, and they assessed the organization independently of each other. There were three suggested changes for organization made by the professors with regard to topic, which the researcher incorporated into the analysis. There were no suggested changes for organization of verbal structures. In addition to analyzing topics and verbal structures, the researcher looked for instances of negotiation for meaning and negotiation of verbal form to further explore the nature of the interaction between the participants.

\section{Results}

\subsection{Analysis of Topic and Vocabulary}

The recorded data revealed a wide range of topics that come from four proficiency levels. This result indicated that learners used a variety of complexity of vocabulary during their conversations. Nonetheless, it was observed that not all learners were able to participate in all topics of conversation. The topics are grouped by proficiency level in Table 2.

The Beginner level subjects all utilized fairly simple and common, everyday vocabulary that is introduced first in most programs. All participants were able to easily comment on these topics and there did not appear to be any problems or conversation breakdowns when expressing ideas, i.e. there were no instances of negotiation of meaning. In addition, the Beginning topics were identified by their focus on the here and now. These topics identify the participants as university students and tend to be very general and/or short parts of conversations without a lengthy discussion or explanation. Statements related to these topics included basic descriptions that relied heavily on nouns and adjectives. In many cases the Beginner topics led to the use of formulaic expressions and introductory questions learned early on during the first semester of Italian. For example in Excerpt 1: two students (Lorenzo and Davide) are greeting each other:

\section{Excerpt 1: Greeting}

1 L: Ciao, Davide. [Come] ${ }_{1}$ Hi, Davide. $[\mathrm{How}]_{1}$

2 D: $[\mathrm{Ciao}]_{1}$ $[\mathrm{Hi}]_{1}$

3 L: stai? [laughs] are you

4 D: Bene, e tu? Fine, and you?

5 L: Bene, bene Fine, fine

In this brief exchange we can see an almost exact replica of the first greetings learned in Beginning Italian using the formulaic answer "Bene, e tu?". While this is an appropriate response, it can still be considered formulaic in that participants very rarely expanded beyond this response when answering a "How are you?" question, and yet all participants had an opportunity to respond to such a question within the data set. Only once did a participant break away from this response to speak about a particularly bad day that she had experienced. It 
Table 2. Topics of conversation arranged by complexity.

\begin{tabular}{|c|c|c|c|}
\hline Beginner level & Advanced Beginner level & Intermediate level & Advanced level \\
\hline $\begin{array}{l}\text { greetings } \\
\text { weather } \\
\text { family } \\
\text { current classes } \\
\text { major of study } \\
\text { Italian instructors } \\
\text { friends } \\
\text { Italian food }\end{array}$ & $\begin{array}{l}\text { plans for the weekend } \\
\text { plans for the summer } \\
\text { traveling to Italy in the future } \\
\text { study abroad } \\
\text { Italian culture } \\
\text { last weekend } \\
\text { last summer }\end{array}$ & $\begin{array}{l}\text { popular culture: opinions on TV, } \\
\text { movies, music, celebrities } \\
\text { romantic relationships: problems } \\
\text { and advice } \\
\text { college drinking, drinking age }\end{array}$ & $\begin{array}{l}\text { linguistics } \\
\text { American politics: presidential election } \\
\text { Italian politics: presidential election } \\
\text { Holocaust }\end{array}$ \\
\hline
\end{tabular}

was also observed that Beginner topics tended to be at the beginning of conversations possibly serving as small talk as a means of entering into conversations with new interlocutors.

Advanced Beginner topics were similar in that the vocabulary was common to everyday speech and did not typically appear to present problems for speakers. All learners expect for one beginner, Stefania, were able to successfully speak about these topics. Stefania did try to participate in conversations using these topics but in all cases she abandoned the topic, usually with a long pause followed by a statement of a lack of knowledge (most commonly Non lo so "I don't know"). Different from the vocabulary used for Beginner level topics, there were four instances of negotiation for meaning found during these interactions. When these breakdowns occurred they were all successfully repaired with information from others within the main conversation, or through petitions of assistance to other group members. An example of this type of Advanced Beginner topic is found in Excerpt 2, below, wherein three students (Amelia, Giovanni, and Nicola) and the researcher (R) are talking about study abroad which leads to comments about Italian music. One of the NSs (Pietro) was present at the time but does not participate in this portion of the conversation until petitioned for a lexical item.

\section{Excerpt 2: Italian music}

1 R: ma, tu studi in Italia queste estate? sì? but, you're studying in Italy this summer? right?

2 A: sì, vado con uh [university name] yes, I'm going with uh [university name]

$3 \mathrm{~N}$ : io sono andato l'anno [scorso $]_{1}$ I went last [year $]_{1}$

4 A: $[o h]_{1}$ Com'è? uh... wait no, Come è stato? $[o h]_{1}$ How is it? uh... wait no, How was it?

$5 \mathrm{~N}$ : Bene, benissimo... uh mi piace molto Roma e... Fine, great... uh I like Rome a lot and...

6 G: Anche io sono andato a Roma... mi piace molto ma ho... spe- spenso? molti soldi? I also went to Rome... I like it a lot but I... (made-up word) a lot of money?

7 R: uh... speso? hai speso molti soldi? uh... spent? you spent a lot of money?

8 G: Sì, sì, speso yes, yes, spent

9 A: Perche hai uh... speso? molti soldi? Why did you uh... spend? a lot of money?

10 G: Ho comprato molte cose, uh... regali, libri, uh film e uh CDs I bought a lot of things, uh... gifts, books, uh movies and uh CDs

$11 \mathrm{~N}$ : CDs? Ti piace la musica italiana? CDs? Do you like Italian music?

12 G: Sì, ci sono uh gruppo... gruppi di musica hip-hop (pronounced with Italian accent) Yes, there are uh group... hip-hop music groups

$13 \mathrm{~N}$ : $E w$, non mi piace musica italiana molto... uh è uh molto... uh.. um... cheesy? [laughs]

Ew, I don't like Italian music a lot... uh it's uh very... uh... um... cheesy? [laughs]

14 G: Sì, è un po' uh cheesy. [laughs] Come si dice cheesy? 
Yes, it's a little uh cheesy. [laughs] How do you say cheesy?

15 A: [laughing] Non lo so... uh, Pietro, come si dice cheesy in italiano?

[laughing] I don't know... uh, Pietro, how do you say cheesy in Italian?

16 P: Hmm... penso che "sdolcinato" sia la parole que vuoi, ma...

Hmm... I think "cheesy" is the word you want, but...

While these Advanced Beginner topics required more sophisticated vocabulary (and verbal structures, discussed below), the conversation remained fairly superficial and topics tended to change quickly (approximately 20 turns or fewer). As can be seen here, the discussion of study abroad and music is fairly simple, expressing basic plans, reporting events, and expressing likes and dislikes. When Nicola wishes to explain why he does not care for Italian music he has difficulty with vocabulary and does not expand on his explanation. The other speaker, Giovanni, also follows this pattern of a superficial discussion in that he does not explain why he likes the music, but rather only identifies the type of music and then later agrees with Nicola's adjective.

There are two instances of vocabulary problems in this excerpt, the first ${ }^{4}$ occurs in line 6 where Giovanni does not know the correct word for spent and uses a created approximation of the Italian and English words with a rising tone indicating a potential vocabulary problem. The researcher provides him with the correct term in line 7 which Giovanni then confirms in line 8. Also of interest here is that Amelia then uses it immediately in line 9 to ask a question to continue the conversation, reinforcing the correction. When Nicola attempts to explain why he does not like Italian music in line 13 he is unable to express it in Italian and code-switches to English in order to make his point. This in turn leads the conversation away from music to a meta-linguistic discussion about the word cheesy with L2 information coming from a NS.

At the Intermediate level there was a shift to more sophisticated speech involving talk about opinions, personal problems, and giving advice to others. Excerpt 3 below provides an example where two students (Lorenzo and Davide) and the researcher (R) discuss the drinking age and college drinking. These topics required both more precise vocabulary and often the use of the subjunctive mood. Unlike the Advanced Beginner level, here participants were able to better explain their reasons for their opinions. Conversations were able to build from a more basic topic, such as talking about one's plans for the weekend with a significant other (an Advanced Beginner topic), to more advanced conversations, such as the problem that person was having with the significant other. Intermediate topics allowed participants to produce longer utterances and longer overall conversations (around 20 to 35 turns). There were five instances of communication breakdowns due to vocabulary for these topics, but only three of these resulted in negotiation for meaning. For the other two, one resulted in topic change and the other relied on code-switching to English.

These Intermediate level conversations showed a smaller population within the overall participant group in that three of the learners-Stefania, Sergio and Nicola — did not participate in conversations using the intermediate level topics. Based on her failed attempts at participating in the Advanced Beginner conversations, it can be speculated that Stefania avoided Intermediate topic conversations because she was not able to understand them. For Sergio and Nicola, there is not enough data to know if they were capable of participating or not; it can only be reported that they did not produce any utterances within the topics at the Intermediate level. Nonetheless, as noted by the researcher, Sergio and Nicola appeared to become observers of the more advanced conversations, or they began a second conversation with another interlocutor at a more basic level.

\section{Excerpt 3: Drinking age}

1 L: Vuoli una birra? ho tutto... uh... un pitcher [laughter] Do you want a beer? I have... uh... un pitcher

2 R: Grazie. Sai che in alcuni.. uh.. stati loro... uh... cambier- cambierà l'eta di bere? Thanks. Did you know that in some... uh... states they... uh... are chang-changing the drinking age?

3 L: no, non è possibile no, that's not possible

4 R: sì, ho sentito sulla radio [stamattina $]_{1} \ldots$ yes, I heard on the radio [this morning $]_{1} \ldots$

5 L: [ma $]_{1}$, loro non possono.. uh possono cambiare.. la legge dello...

${ }^{4}$ This vocabulary problem may also be viewed as a verbal structure problem since the participant struggles with the past participle. However, his created word demonstrates knowledge of an irregular participle and the correct use of the auxiliary verb and was therefore determined to be a vocabulary problem instead of a verbal structure problem by the researcher. 
$[\text { but }]_{1}$, they can't... uh can't change... the law of the...

6 R: possono, ma devono uh pagare uh una mul-? multa they can, but they have to uh pay uh a fi-? fine

7 L: sì, sì, ma questo non è nu- nuovo yes, yes, but this is not ne- new

8 R: no?

no?

9 L: gli stati sempre uh hanno [cough] la possibilità di pagare per... uh avere un'eta di bere minore states always uh have [cough] the possibility of paying to... uh to have a younger drinking age

10 D: Penso che sia stupido pagare una multa per quello I think it's stupid to pay a fine for that

11 L: Perché? se una persona può morire per uh gli uh St-stati uniti... Why? if a person can die for uh the uh $U$-united States...

12 R: sì, hanno detto che uh in alcuni stati è solamente uh per uh... i miliatri yes, they said that uh in some states it's only uh for uh... the military

13 D: non capisco perché gli studenti uh vogliono bere... o essere... ubriacchi... secondo meI don't understand why students uh want to drink... or be... drunk... in my opinion-

14 L: -ma, le persona piace alcol... è diver-but, people like alcohol... it's XX-

15 D: -ma secondo me è stupido, non lo capisco -but in my opinion it's stupid, I don't understand it

16 R: ma tu non bevi, Davide but you don't drink, Davide

17 D: no, mai no, never

18 L:well, come puoi dire XXX...che è stupido? well, how can you say XXX... that it's stupid?

19 D: bene, penso che sia stupido... perdere la mente così... o fare cose stupide well, I think that it's stupid... to lose your mind like that... o do stupid things

In Excerpt 3 it is possible to see Lorenzo and Davide form their arguments, explain their point of view, and even challenge each other's ideas. It can also be seen here that the utterances are longer and that ideas are expressed over several turns in a back-and-forth exchange of ideas. In the lower level conversations, ideas were often confined to one turn and given the superficial nature of the lower-level topics an argument style conversation was not present.

At the Advanced level, there was a continuation of more complex conversations including more intricate arguments and explanations. These topics continued in their level of difficulty due to the vocabulary needed and the structures that were used to best explain one's point. Advanced topics were limited to only four of the participants, Davide, Lorenzo, Maria and Teresa, and often included the two NSs in addition to the L2 speakers. During data collection, the researcher noted that these conversations were less likely to be observed by other lower-level speakers than were the Intermediate and Advanced Beginner conversations. As with Intermediate topics, the ideas expressed used multiple turns and longer utterances than in the Beginner and Advanced Beginner levels (approximately 15 to 36 turns). At this level, there were two instances of breakdowns due to vocabulary that were resolved with negotiation with the other interlocutors involved in the conversation. At this level there were no instances of solicitation to others outside of the conversation. Of interest here, most vocabulary problems were solved by the speaker before they could result in a breakdown. This type of lexical self-correction was not seen in any other level (an example of this is seen in Excerpt 4 below in line 1).

One of the topics that came up often was the Holocaust and Italy's involvement in World War II; this was most likely due to the fact that several of the students were taking a course on this topic. In Excerpt 4 two students (Lorenzo and Maria) discuss the concept of Primo Levi’s (1986) Grey Zone ${ }^{5}$ and the Holocaust:

${ }^{5}$ Primo Levi was an Italian Holocaust survivor who wrote several books on the subject. One of his most controversial ideas is the Grey Zone which explains how many survivors made compromises with the Nazis to stay alive and that being pro-Nazi or anti-Nazi is not as black and white as it may first appear (Levi, 1986). 


\section{Excerpt 4: The Holocaust}

1 L: Qual'è il tuo tema per uh... il paper uh... progetto finale?

What's your topic for uh... the paper uh... final project?

2 M: Scrivo della Zona Grigia e come Levi dice uh che non uh è possibile... giu- giudicare quelle persone, i sopravissute... sopravissuti

I'm writing about the Grey Zone and how Levi says uh that it's uh not possible... to ju-judge those people, the survivors (wrong gender)... survivors (correct gender)

3 L: ah, sì, anch'io scrivo della Zona Grigia. Che ne pensi del partito di calcio con gli SSah, yes, I too am writing about the Grey Zone. What do you think about the soccer game with the SS-

4 M: -il partito con gli SS e uh i Soderkommandos? ${ }^{6}$ Ho un articolo di quello-the game with the SS and uh the Soderkommandos? I have an article about that-

5 L: -sì, ho quello articolo... per me è una rapprenzentazione uh della banalità di uh malvagio -yes, I have that article... for me it's a representation uh of the banality of uh evil

6 M: sono d'accordo, com'è possibile che loro hanno giocato calcio mentre... uh molto vicino a loro c'erano un gruppo di ebrei che morivano? Per me, mostra la crudeltà dei nazisti e il uh suo... uh il loro indifferenza...

I agree with you, how is it possible that they played soccer while... uh very close to them there was a group of Jews dying?For me, it shows the cruelty of the Nazis and uh his... uh their indifference...

$7 \mathrm{~L}$ : ma anche è importante considerare quegli prigioneri che hanno giochato con loro... but also it's important to consider those prisoners that played with them...

\section{M: sì}

yes

9L: loro hanno responsibilità... XXX parte della responsibilità... se loro avessero rifiutato il lavoro, uh sarebbero morti, ma uh... sarebbero morti con uh la dignità

they have responsibility... XXX part of the responsibility... if they had refused the job, uh they would have died, but uh... they would have died with uh dignity

$10 \mathrm{M}$ : ma, quello è il punto principale di Levi... non è possiblie dire che loro avrebbero avuto più dignità, uh non uh non è la nostra decisione, noi non possiamo capire-

but, that is Levi's principle point... it's not possible to say that they would have had more dignity, uh it's not uh it's not our decision, we can't understand-

11 L: -ma

-but

12 M: non possiamo capire perche siamo fuori della Zona Grigia we can't understand because we are outside of the Grey Zone

In this excerpt we see a more complex argument where both students are discussing an emotionally-charged and grave topic and are using rhetorical questions, hypothetical situations, and longer explanations of their point of view. This example also shows the use of less common vocabulary, such as judge, survivors, banality, and evil.

After analysis of the range of complexity of topics, the researcher was curious as to the portions of the total conversation that each level of complexity represented. By calculating the percentage of each level of topic over the total amount of conversations, it was found that Beginner topics accounted for $18.14 \%$ of the total conversation, Advanced Beginner topics were $27.47 \%$, Intermediate topics were $41.67 \%$, and Advanced topics were $12.72 \%$. Thus although a range of topics was found, we can see that the majority of the topics were at the Intermediate and Advanced Beginner level (69.14\% of the total conversation).

\subsection{Analysis of Verbal Structures}

The data were next analyzed for verbal structures as a method for assessing their grammatical complexity throughout the conversations. It should be noted that unlike topic where the learner has some level of choice and control, the use of verbal structures is more rigid in that a learner is only capable of producing the structures that she knows. The results found that there were a range of structures in four proficiency levels found in the data that are summarized below in Table 3.

The most common verbal structures used were those found in the Beginner level with $64.25 \%$ of the verbs in

\footnotetext{
${ }^{6}$ Soderkommandos were the prisoners forced to work at the gas chambers in Auschwitz (Levi, 1986).
} 
either the present indicative or present progressive forms, followed by Advanced Beginner level with 19.34\%, then Intermediate structures with $15.66 \%$, and finally Advanced structures which were the least utilized at 0.75\%. All participants produced the structures in the Beginner and Advanced Beginner levels in various conversations. Of these, the present indicative was most prevalent throughout the data in that it could be utilized for all of the topics mentioned in the previous section. It is worth noting, that one of the participants, Stefania, only produced the preterit (passato prossimo) structure out of the three verbal structures at the Advanced Beginner level. Based on this and her use of topics, Stefania was likely the least advanced speaker of the participant group.

It is important to note, however, that verbal structure was not always aligned with level of topic. There were many instances where a topic might be considered to be at a lower level, yet a participant was able to use a more advanced structure within that conversation. For example when offering opinions learners could use the present tense indicative (less difficulty) or subjunctive (higher difficulty) depending on how they introduced the opinion. The participants who could be classified as Beginner or Advanced Beginner-Stefania, Sergio, Violeta and Nicola - showed no examples of the subjunctive in their speech, but, with the exception of Stefania, they did show an occasional use of the conditional with the phrase mi piacerebbe "I would like" which is introduced in first-year Italian. So, while most participants were able to produce the structures at the Intermediate level, only six of them used these structures in a variety of conversations with a variety of verbs.

The Advanced structures, although present, were not widely used and represent less than $1 \%$ of the participants' verbal structures. By using more advanced structures the participants identify themselves as more competent speakers and more knowledgeable about Italian. Only three participants, Lorenzo, Maria and Teresa, produced these structures, with most coming from Lorenzo and Maria. Of note, these structures were also rarely used by the native speakers themselves, and it is possible that such structures are more common in written Italian than spoken Italian.

With regards to communication breakdowns due to verbal structures, there were only three instances of this type of breakdown found in the data. Two of these occurred when a learner used the present tense indicative for actions in the past, and in both cases other learners asked for clarification about the time of the activity discussed. In one case the learner was able to self-correct to the correct preterit form after the clarification request. In the other case, the correct form was provided by another learner as part of a clarification question. In the third breakdown, a learner incorrectly used the conditional form to create an unintelligible utterance. Although a clarification request was made and the learner attempted to rephrase the utterance, the learner ultimately abandoned his utterance and changed the topic.

\section{Discussion and Conclusion}

Returning to the first research question, do learners show a range of topic and vocabulary complexity during conversations? We can see that yes, learners do show a range of complexity in their topics and vocabulary used during the conversation sessions. This is a positive result because it shows that learners in this dataset did not use only easy or basic topics of conversation but they challenged themselves to produce difficult topics of conversation without encouragement from an instructor or moderator. While an instructor or moderator may be helpful to assist in topic maintenance and encouraging participation as with Ziegler et al. (2013), too much participation from the moderator may be detrimental to the success of the group (McDonough \& Hernández González, 2013). The findings here reveal that learners are certainly capable of maintaining diverse conversation topics in the L2 on their own. Additionally, if learners are not about to participate in the more advanced conversations, they may also be content to observe these conversations as was seen in Ziegler et al. (2013). Nevertheless, we can see that most conversation used Intermediate or Advanced Beginner level topics. This result may be considered surprising given that the majority of the participants were enrolled in Advanced classes; however, the overall nature of

Table 3. Verbal structures used arranged by complexity ${ }^{7}$.

\begin{tabular}{llll}
\hline Beginner level & Advanced beginner level & Intermediate level & Advanced level \\
\hline $\begin{array}{l}\text { present indicative } \\
\text { present progressive }\end{array}$ & preterit (passato prossimo) & present subjunctive & conditional perfect \\
& imperfect & conditional & imperfect subjunctive \\
\hline
\end{tabular}

${ }^{7}$ This table is additive in that only the newer verbal structures are indicated as level increases. Therefore, for example, the Intermediate level would also contain the verbal structures in the Beginner and Advanced Beginner levels. 
conversation in this group could be seen as more social and closely related to student life lending itself to the types of topics found in Intermediate and Advanced Beginner courses rather than the deeper, more intellectual topics found in the Advanced level. In informal discussions with the researcher, it was discovered that many of the students had become friends through participating in the Italian Table and as such it is not surprising that their Italian conversations would focus on their own lives and relationships. When taking a closer look at the use of the Advanced topics, it was found that most of these topics were introduced through a personal connection with the topic. This can be seen in Excerpt 4, were Lorenzo introduces the topic if the Holocaust by asking about final project papers that both he and his interlocutor were completing at the time.

Similar to Question 1, the second research question asked if learners showed a range of verbal structure complexity during conversations. We can see that once again the answer is yes, the learners in this study also used a range of verbal structures from Beginner level forms to Advanced forms. Also similar to the results of Question 1, learners tended to use the lower level forms much more frequently than the higher level forms. Here a link between verbal form and topic can be found in that less-complex topics tended to lend themselves to less-complex verb forms. Frequency of use notwithstanding, it was encouraging to see that learners were willing to use more difficult forms, especially the subjunctive which is notorious for avoidance (e.g. Hubert, 2011), again without prompting by an instructor or moderator. In particular, the use of the subjunctive appeared to be a way for learners to distinguish themselves as being above the Advanced Beginner level, despite using everyday vocabulary for a more basic topic. An example of this was when participants were providing opinions, and opted to use a phrase requiring subjunctive such as penso che "I think that", rather than a phrase that does not require subjunctive like secondo me "in my opinion". While the verb pensare "to think" is introduced in the beginning level and is a fairly common word in everyday language, the knowledge of using it with the subjunctive represents a higher proficiency level. This use of the subjunctive for opinions may also reflect a move towards a more native-like speech style by the advanced students not unlike the change in style seen in Ziegler et al. (2003) where learners shifted towards a more German-like style of conversation over time.

The final research question focused on whether or not learners would engage in negotiation during their conversations. Results revealed that yes there was some negotiation during the conversations, but it did not appear to be as frequent as in other research studies that were designed to promote it (Bruton \& Samuda, 1980; Long \& Porter, 1985; Ohta, 1995; Pica, Lincoln-Porter, Paninos, \& Linnell, 1996; Mackey, 1999; Del Pilar García Mayo \& Pica, 2000; Mackey, Oliver, \& Leeman, 2003; Adams, 2007; Sato \& Lyster, 2007; Sato, 2007; Fernández Dobao, 2012). This finding speaks to the type of atmosphere that was created in the conversation group. As with Sato and Lyster (2007) and Sato (2007), the interaction between the learners followed a more relaxed and low-pressure style of interaction, where learners felt comfortable seeking assistance from others. However, it seemed that these learners were also comfortable with allowing errors to happen and focused more on practicing speaking and maintaining a conversation rather than being concerned with linguistic accuracy. The nature of the negotiation between learners focused on meaning more than form. This is understandable given that a misused vocabulary item appears to have been more disruptive for these learners than incorrect verbal forms. Similar to findings by Ohta (1995), it appears as though these learners had a tendency to ignore verbal errors rather than to provide feedback on them. As this was an exploratory investigation, in-depth analysis of the type of feedback and the nature of modified output was not completed at this time, but should be considered for future research into conversation groups to discover whether or not natural conversations will lend themselves to similar beneficial interaction that is found in classroom and laboratory tasks.

The implications of this research show that conversation groups can offer L2 learners opportunities for naturalistic speech practice that both reinforces known L2 information and challenges learners to produce high quality conversation. However, such a relaxed atmosphere without instructor or moderator leadership may not lend itself to an environment with high levels of negotiation and corrective feedback. Thus if the goal is to provide greater amounts of form-focused information, more involvement by instructors may be necessary. Yet, if the goal is to provide a social, communication activity, this type of student-dominated context seems ideal. What remains to be seen is the impact that participation in conversation groups of this nature can have on learner's linguistic abilities. Therefore continued research into conversation groups should focus on the learning potential for students as a means of greater understanding of the value of this conversational practice.

\section{Acknowledgements}

I wish to thank the participants of the Italian Table for their support and willingness to participate in this study. I 
also thank my peer reviewers for their time in reviewing this paper and for their comments on my work.

\section{References}

Adams, R. (2007). Ch. 1: Do Second Language Learners Benefit from Interacting with Each Other? In A. Mackey (Ed.), Conversational Interaction in Second Language Acquisition (pp. 29-51). Oxford: Oxford University Press.

Bruton, A., \& Samuda, V. (1980). Learner and Teacher Roles in the Treatment of Oral Error in Group Work. RELC Journal, 2, 49-63. http://dx.doi.org/10.1177/003368828001100204

Del Pilar García Mayo, M., \& Pica, T. (2000). L2 Learner Interaction in a Foreign Language Setting: Are Learning Needs Addressed? International Review of Applied Linguistics in Language Teaching, 38, 1-22. http://dx.doi.org/10.1515/iral.2000.38.1.35

Fernández Dobao, A. (2012). Collaborative Dialogue in Learner-Learner and Learner-Native Speaker Interaction. Applied linguistics, 33, 229-256. http://dx.doi.org/10.1093/applin/ams002

Gass, S. M. (1997). Input, Interaction, and the Second Language Learner. Hillsdale, NJ: Erlbaum.

Glaser, B., \& Strauss, A. L. (1967). The Discovery of Grounded Theory: Strategies for Qualitative Research. Chicago: Aldine.

Hubert, M. D. (2011). Foreign Language Production and Avoidance in US University Spanish-Language Education. International Journal of Applied Linguistics, 21, 222-243. http://dx.doi.org/10.1111/j.1473-4192.2010.00276.x

Levi, P. (1986). I Sommersi e i Salvati. Italy: Einaudi.

Long, M. H. (1983). Linguistic and Conversational Adjustments to Non-Native Speakers. Studies in Second Language Acquisition, 5, 177-193. http://dx.doi.org/10.1017/S0272263100004848

Long, M. H., \& Porter, P. A. (1985). Group Work, Interlanguage Talk, and Second Language Acquisition. TESOL Quarterly, 19, 207-228. http://dx.doi.org/10.2307/3586827

Mackey, A. (1999). Input, Interaction, and Second Language Development. Studies in Second Language Acquisition, 21, 557-587. http://dx.doi.org/10.1017/s0272263199004027

Mackey, A. (2007). The Role of Conversational Interaction in Second Language Acquisition. In A. Mackey (Ed.), Conversational Interaction in Second Language Acquisition (pp. 1-26). Oxford: Oxford University Press.

Mackey, A., Oliver, R., \& Leeman, J. (2003). Interactional Input and the Incorporation of Feedback: An Exploration of NSNNS and NNS-NNS Adult and Child Dyads. Language Learning, 53, 35-66. http://dx.doi.org/10.1111/1467-9922.00210

McDonough, K., \& Hernández González, T. (2013). Chapter 15: Language Production Opportunities during Whole-Group Interaction in Conversation Group Settings. In A. Mackey, \& K. McDonough (Eds.), Second Language Interaction in Diverse Educational Contexts (pp. 293-314). Amsterdam: John Benjamins Publishing Company. http://dx.doi.org/10.1075/lllt.34.20ch15

Ohta, A. S. (1995). Applying Sociocultural Theory to an Analysis of Learner Discourse: Learner-Learner Collaborative Interaction in the Zone of Proximal Development. Issues in Applied Linguistics, 6, 93-121.

Pica, T. F., Lincoln-Porter, F., Paninos, D., \& Linnell, J. (1996). Language Learners’ Interaction: How Does It Address the Input, Output, and Feedback Needs of Learners? TESOL Quarterly, 30, 59-84. http://dx.doi.org/10.2307/3587607

Sato, M. (2007). Social Relationships in Conversational Interaction: Comparison of Learner-Learner and Learner-NS Dyads. JALT Journal, 29, 183-208.

Sato, M., \& Lyster, R. (2007). Chapter 5: Modified Output of Japanese EFL Learners: Variable Effects of Interlocutor versus Feedback Types. In A. Mackey (Ed.), Conversational Interaction in Second Language Acquisition (pp. 123-142). Oxford: Oxford University Press.

Swain, M. (1993). The Output Hypothesis: Just Speaking and Writing Aren’t Enough. The Canadian Modern Language Review, 50, 158-164.

Swain, M. (2000). The Output Hypothesis and beyond: Mediating Acquisition through Collaborative Dialogue. In J. P. Lantolf (Ed.), Sociocultural Theory and Second Language Learning (pp. 97-114). Oxford: Oxford University Press.

Tudini, V. (2013). Form-Focused Social Repertoires in an Online Language Learning Partnership. Journal of Pragmatics, 50, 187-202. http://dx.doi.org/10.1016/j.pragma.2012.12.005

Ziegler, N., Seals, C., Ammons, S., Lake, J., Hamrick, P., \& Rebuschat, P. (2013). Chapter 14: Interaction in Conversation Groups: The Development of L2 Conversational Styles. In A. Mackey, \& K. McDonough (Eds.), Second Language Interaction in Diverse Educational Contexts (pp. 269-292). Amsterdam: John Benjamins Publishing Company.

http://dx.doi.org/10.1075/lllt.34.19ch14 